\title{
Membrane lipid unsaturation as physiological adaptation to animal longevity
}

\section{Alba Naudí ${ }^{1}$, Mariona Jové ${ }^{1}$, Victòria Ayala ${ }^{1}$, Manuel Portero-Otín ${ }^{1}$, Gustavo Barja ${ }^{2}$ and Reinald Pamplona ${ }^{1 *}$}

1 Department of Experimental Medicine, University of Lleida-Biomedical Research Institute of Lleida (UdL-IRBLleida), Lleida, Spain

2 Department of Animal Physiology II, Complutense University, Madrid, Spain

\section{Edited by:}

Angel Catala, CONICET, Universidad

Nacional de La Plata, Argentina

\section{Reviewed by:}

Mario L. Diaz, Universidad de La

Laguna, Spain

Mustafa Naziroglu, Süleyman

Demirel University, Turkey

\section{*Correspondence:}

Reinald Pamplona, Departament de Medicina Experimental, Universitat de Lleida-Institut de Recerca Biomédica de Lleida, Edifici

Biomedicina 1, Avda. Rovira Roure

80, Lleida 25198, Spain

e-mail: reinald.pamplona@

mex.udl.cat

\begin{abstract}
The appearance of oxygen in the terrestrial atmosphere represented an important selective pressure for ancestral living organisms and contributed toward setting up the pace of evolutionary changes in structural and functional systems. The evolution of using oxygen for efficient energy production served as a driving force for the evolution of complex organisms. The redox reactions associated with its use were, however, responsible for the production of reactive species (derived from oxygen and lipids) with damaging effects due to oxidative chemical modifications of essential cellular components. Consequently, aerobic life required the emergence and selection of antioxidant defense systems. As a result, a high diversity in molecular and structural antioxidant defenses evolved. In the following paragraphs, we analyze the adaptation of biological membranes as a dynamic structural defense against reactive species evolved by animals. In particular, our goal is to describe the physiological mechanisms underlying the structural adaptation of cellular membranes to oxidative stress and to explain the meaning of this adaptive mechanism, and to review the state of the art about the link between membrane composition and longevity of animal species.
\end{abstract}

Keywords: fatty acid biosynthesis, membrane unsaturation, oxidative damage, peroxidizability index, phylogenomic analysis, rate of aging, reactive carbonyl species

\section{INTRODUCTION}

The appearance of oxygen in the terrestrial atmosphere represented an important selective pressure for ancestral living organisms and contributed toward setting up the pace of evolutionary changes in structural and functional systems (McCord, 2000; Lane, 2002; Embley and Martin, 2006; Pamplona and Costantini, 2011). The evolution of using oxygen for efficient energy production served as a driving force for the evolution of complex organisms (Lane, 2002; Schirrmeister et al., 2013). The redox reactions associated with its use were, however, responsible for the production of reactive species [reactive oxygen species (ROS) and reactive carbonyl species (RCS)] with damaging effects due, basically, to oxidative chemical modifications of essential cellular components (Halliwell and Gutteridge, 2007). Consequently, aerobic life required the emergence and selection of antioxidant defense systems (Halliwell, 1999). As a result, a high diversity in molecular and structural antioxidant defenses evolved (Pamplona and Costantini, 2011). Nevertheless, the balance between oxidant production systems and antioxidant defenses is adjusted in a species-specific way to generate a net flux of oxidant (see Figure 1) for maintaining antioxidant responses through redox signaling pathways perfectly integrated in the cellular metabolic machinery. This oxidative stress has become a universal constraint of life-history evolution in animals and a modulator of phenotypic development (Dowling and Simmons, 2009; Pamplona and Costantini, 2011).
Living organisms on the Earth which are divided into three major domains-Archaea, Bacteria, and Eucarya-, probably came from a common ancestral cell. The cell membrane is a key dynamic structural component of a cell, and lipid molecules are essential for cell membranes (Itoh et al., 2001; Lombard et al., 2012). All cell membranes are composed of glycerol phosphate phospholipids, and this commonality argues for the presence of such phospholipids in the last common ancestor (Lombard et al., 2012). Therefore, all living organisms have lipid membranes.

Biological membranes are dynamic structures that generally consist of bilayers of amphipathic molecules held together by non-covalent bonds (Yeagle, 1993; Vance and Vance, 1996). Phospholipids, the predominant membrane lipids in eukaryotic cells, are made up of a glycerol backbone with a hydrophilic headgroup bound to carbon 3, and fatty acids to $\mathrm{C} 1$ and $\mathrm{C} 2$. Phospholipids are a large group of diverse molecules that participate in a wide range of biological processes (Dowhan, 1997). This diversity requires complex metabolic and regulatory pathways (Yeagle, 1993; Vance and Vance, 1996). Indeed eukaryotic cells, to monitor cell membrane composition and to adjust lipid synthesis accordingly (Dobrosotskaya et al., 2002), invest around $5 \%$ of their genes to synthesize all of these lipids (Van Meer et al., 2008).

The phospholipid acyl chains are saturated (SFA), monounsaturated (MUFA), or polyunsaturated (PUFA) hydrocarbon chains that normally vary from 14 to 22 carbons in length (Wallis et al., 2002). In eukaryotic cells from vertebrate species, for example, 


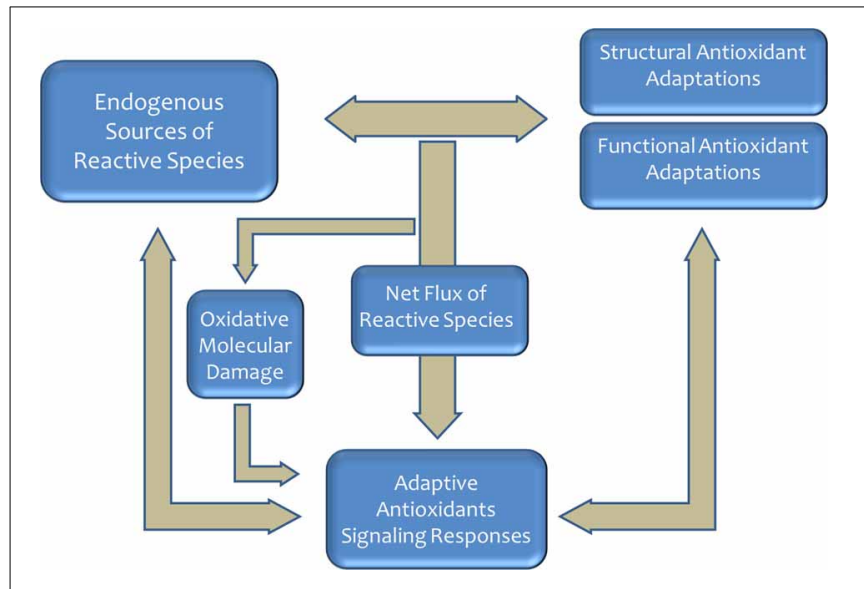

FIGURE 1 | Aerobic life produces reactive species that required the emergence and selection of antioxidant defense systems. Redox state is an important selective pressure faced by most organisms, and a myriad of mechanisms have evolved to regulate and adjust this process. In homeostatic conditions, the sytem play a key role in the aging process and the determination of the longevity.

the average chain length of a biological membrane is strictly maintained around 18 carbon atoms, and the relative distribution between SFAs and UFAs follows a ratio of 40:60 (Pamplona, 2008). Substrate precursors for UFA biosynthesis are generally SFA that are products of fatty acid synthase (FAS), as well as essential fatty acids from dietary sources. The desaturase and elongase enzymes, which are conserved across kingdoms, as well as the peroxisomal beta-oxidation pathway, will allow cells to obtain all the diversity of fatty acids present in a cellular membrane (Nakamura and Nara, 2004; Guillou et al., 2010) (see Figure 2). Finally, the deacylation-reacylation cycle will be the mechanism responsible for the particular fatty acid composition of cell membranes.

In the following paragraphs, we analyze the adaptation of biological membranes as dynamic structural defense against reactive species evolved by animals. In particular, our goal is to describe the physiological mechanisms underlying the structural adaptation of cellular membranes to oxidative stress and to explain the meaning of this adaptive mechanism, and to review the state of the art about the link between membrane composition and longevity of animal species.

\section{LIPID PEROXIDATION OF BIOLOGICAL MEMBRANES: SIGNALING vs. CITOTOXICITY}

The physico-chemical properties of the membrane bilayer and the chemical reactivity of the fatty acids that compose the membrane are two inherent traits of the membrane phospholipids that determine their susceptibility to oxidative damage (Pamplona et al., 2002a,b,c; Hulbert et al., 2007; Pamplona, 2008). The first property is related to the fact that oxygen and reactive species are more soluble in the fluid lipid bilayer than in the aqueous solution (Moller et al., 2005; Gamliel et al., 2008). Consequently, membrane lipids become primary targets of oxidative damage. The second and more significant property is related to the fact that PUFA residues of phospholipids are extremely sensitive to oxidation, their sensitivity increasing exponentially as a function of the number of double bonds per fatty acid molecule (Holman, 1954; Bielski et al., 1983). Consequently, PUFA side chains (with two or more double bonds) are much more easily attacked by radicals than are SFA (no double bonds) or MUFA (one double bond) side chains. In this scenario, from a given membrane fatty acid profile it is possible to calculate its peroxidizability index (PI) by combining this composition with the relative susceptibility of individual fatty acids to peroxidation. So, PI is an approach to the relative susceptibility of a given membrane fatty acid composition to peroxidative damage. The higher the number the more susceptible, the lower the value of PI, the more resistant to lipid peroxidation is the membrane bilayer (Pamplona et al., 2002a,b,c; Hulbert et al., 2007).

Lipid peroxidation generates hydroperoxides as well as endoperoxides, which undergo fragmentation to produce a broad range of reactive intermediates called RCS with three to nine carbons in length, the most reactive being $\alpha, \beta$-unsaturated aldehydes [4-hydroxy-trans-2-nonenal (HNE) and acrolein], di-aldehydes [malondialdehyde (MDA) and glyoxal], and keto-aldehydes [4oxo-trans-2-nonenal (ONE) and isoketals] (Esterbauer et al., 1991; Catalá, 2009; Zimniak, 2011; Fritz and Petersen, 2013). 2-Hydroxyheptanal and 4-hydroxyhexenal are other significant aldehydic products of lipid peroxidation of PUFAs. These carbonyl compounds, ubiquitously generated in biological systems, have unique properties contrasted with other reactive species. For instance, compared with ROS, reactive aldehydes have a much greater half-life (i.e., minutes to hours instead of nanoseconds to microseconds for most ROS). Further, the non-charged structure of RCS allows them to migrate easily through hydrophobic membranes and hydrophilic cytosolic media, thereby extending the migration distance far from the generation site (Pamplona, 2008).

These compounds have specific physiological signaling roles inducing adaptive responses driven to decrease oxidative damage and improve antioxidant defenses (Pamplona, 2008, 2011; Higdon et al., 2012). Two of these mechanisms involved in the prevention of oxidative damage effects are: (i) the regulation of uncoupling protein activity (Echtay et al., 2003; Brand et al., 2004), and (ii) the activation of the antioxidant response signaling pathway that includes the expression of enzymes such as glutathione-S-transferase (GST) specifically designed to detoxify reactive carbonyl compounds (Wakabayashi et al., 2004; Copple et al., 2008; Giles, 2009; Maher and Yamamoto, 2010). As important as GST is for these adaptive mechanisms, is the role GP $\times 4$ (phospholipid hydroperoxide glutathione peroxidase) has in restoring reduced state of membrane fatty acids from phospholipids to ensure membrane lipid homeostasis (Imai and Nakagawa, 2003; Brigelius-Flohé, 2006; Conrad et al., 2007). GP $\times 4$ gene structure, expression and activity is likely to have evolved in a coherent fashion to cope with prooxidant conditions.

Based on the features mentioned above these carbonyl compounds can be, however, more destructive than ROS and may have far-reaching damaging effects on target sites within or outside membranes. Carbonyl compounds react with nucleophilic groups in macromolecules (lipoxidation reactions) like proteins (Thorpe and Baynes, 2003), DNA (West and Marnett, 2006), and aminophospholipids (Naudi et al., 2013), among others, resulting 


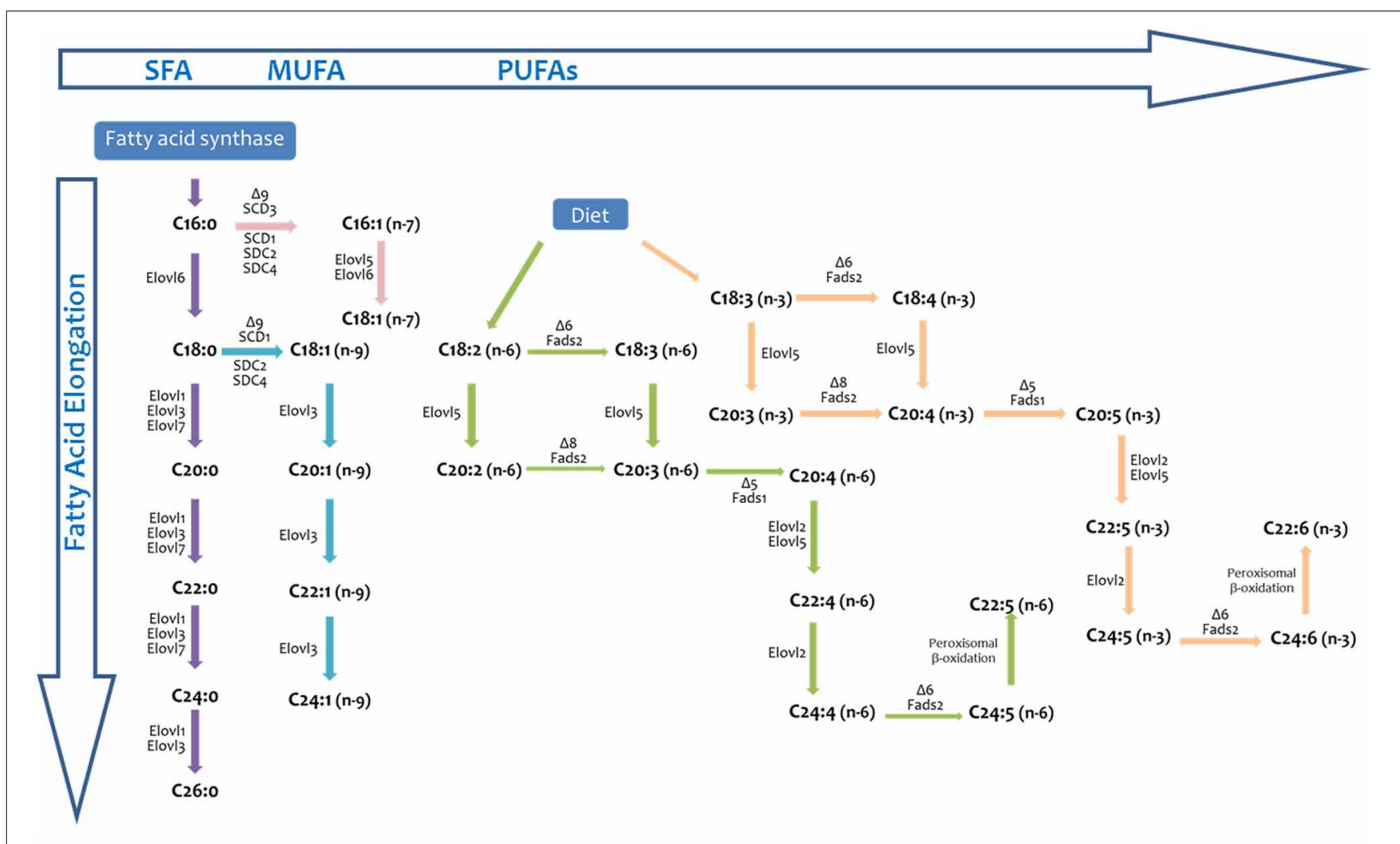

\section{LONGEVITY}

AGING

FIGURE 2 | Long chain and very long-chain fatty acid biosynthesis in vertebrates. The long chain saturated fatty acids and unsaturated fatty acids of the $n-7$ and $n-9$ series can be synthesized from palmitic acid (C16:0) produced by the fatty acid synthase (FAS). Long-chain fatty acids of the $n-6$ and $n-3$ series can only be synthesized from precursors obtained from dietary precursors (DIET). Elovl, elongation of very long chain fatty acids (fatty acid elongase); Fads, fatty acid desaturase. in their chemical, nonenzymatic, and irreversible modification and formation of a variety of adducts and crosslinks collectively named Advanced Lipoxidation Endproducts (ALEs) (Thorpe and Baynes, 2003; Pamplona, 2011).

Consequently, the high concentration of PUFAs in cellular membrane phospholipids not only makes them prime targets for reaction with oxidizing agents but also enables them to participate in long free radical chain reactions. The regulatory function and cytotoxicity of the lipid peroxidation-derived aldehydes hinges on its abundance, reactivity, and half-life. It is plausible to postulate that a low degree of fatty acid unsaturation in cellular membranes could be advantageous by decreasing their sensitivity to lipid peroxidation. This would also protect other molecules against lipoxidation-derived damage. In other words, it is proposed that membrane unsaturation acts as a structural adaptive system and it is related to the animal longevity.

\section{MEMBRANE UNSATURATION AND ANIMAL LONGEVITY}

Findings from different experimental paradigms recently link membrane unsaturation and lipoxidation-derived molecular damage to longevity: (i) changes that occur in individuals during aging; (ii) different maximum longevity that are characteristic of species and the different longevity of strains and specific mutants within species; and (iii) physiological treatments that alter rate of aging and thus longevity.

\section{IS AGING DUE TO INCREASE OF MEMBRANE UNSATURATION AND LIPOXIDATION REACTIONS?}

It has now been documented that there is an age-associated increase in membrane PI and lipoxidation-derived molecular damage (see Table 1). In general, PI increases during aging in an organ-dependent way. This is mainly due to decreases in the less unsaturated linoleic (LA, 18:2n-6) and linolenic (LNA, 18:3n3 ) acids and to increases in the highly unsaturated arachidonic acid (AA, 20:4n-6), and docosotetra- penta- and -hexaenoic [22:4n-3, 22:5n-3, and 22:6n-3 (DHA), respectively] acids. In a similar way, the lipoxidative damage, which has been measured in tissue homogenates and mitochondria, also increases with age. Tissues that are composed of long-lived, postmitotic cells, such as the brain, heart, and skeletal muscle, tend to accrue 
Table 1 | Effect of aging on membrane peroxidizability index and lipoxidation-derived molecular damage in tissues from different species.

\begin{tabular}{|c|c|c|c|c|c|}
\hline Tissue & Species & $\operatorname{Age}(\mathbf{s})$ & $\begin{array}{l}\text { Change with aging } \\
\text { in Peroxidizability } \\
\text { Index (PI) }\end{array}$ & $\begin{array}{l}\text { Change with aging in } \\
\text { Lipoxidation-derived } \\
\text { molecular damage }\end{array}$ & References \\
\hline Whole & Drosophila & From 10 to 50 days & Increase & Increase & Magwere et al., 2006 \\
\hline Whole & Drosophila & From 5 to 40 days & Increase & Increase & Jacobson et al., 2010 \\
\hline Brain & Mouse & 6 vs. 24 months & Increase & Increase & Arranz et al., 2013 \\
\hline Spleen & Mouse & 6 vs. 24 months & Increase & Increase & Arranz et al., 2013 \\
\hline Heart & Rat & 8 vs. 30 months & Increase & Increase & Ayala et al., 2006 \\
\hline Liver & Rat & 8 vs. 30 months & Increase & Increase & Ayala et al., 2006 \\
\hline Liver mitochondria & Rat & $6,18,28$ months & Increase & Increase & Lambert et al., 2004 \\
\hline Liver microsomes and mitochondria & Rat & $6,12,24$ months & Increase & n.d. & Laganiere and Yu, 1993 \\
\hline Erythrocyte membranes & Human & From 20 to 90 years & Increase & n.d. & Rabini et al., 2002 \\
\hline
\end{tabular}

n.d., not determined.

relatively greater amounts of damage than those composed of short-lived non-mitotic cells. In this line, lipofuscin, a complex age-pigment derived from lipoxidation reactions considered a hallmark of aging, also shows an accumulation that correlates with age (Tsuchida et al., 1987; Terman and Brunk, 2004).

The singular importance of membrane unsaturation in the aging process is highlighted by studies showing age-related changes in membrane physico-chemical properties. During aging, the membrane fatty acid profile changes with increased peroxidizable PUFAs (see Table 1). PUFAs have lower melting points than SFAs, and consequently, a relative increase in the PUFA content of a membrane would be expected to render the membrane more fluid. Based solely on the fatty acid composition, membranes from older animals should exhibit greater fluidity than those from younger individuals. Paradoxically, the opposite is systematicaly reported; membrane fluidity decreases with age (reviewed in Hulbert et al., 2007). The reasons for the changes of membrane fluidity can be explained in two ways: (1) a change caused by fatty acid chain composition and (2) a change in the cholesterol content of the membrane. The paradox described above is explained by considering that cellular components undergo increased oxidative damage with time. Because PUFAs are more vulnerable to oxidative attack, they experience greater lipid oxidative damage, and the resulting RCSs have been shown to contribute significantly to membrane rigidity and loss of its function (Laganiere and Yu, 1987, 1993; Yu et al., 1992; Yu, 2005; Naudi et al., 2013). A special mention to the recent indications that membrane microdomains (i.e., rafts) also undergo an aging process not necessarily identical to that in the bulk membrane (given the differential biochemical composition between raft and non-raft domains) (Tomoiu et al., 2007; Ohno-Iwashita et al., 2010; Fabelo et al., 2012). These observations apparently correlate with increased membrane microviscosity that parallels changes in both PUFA and cholesterol (which would have opposed effects), and very interestingly, they appear to be accelerated by neurodegenerative processes.

Studies on possible causes of age-associated increase in membrane unsaturation (see Table 1) indicated that activities of some of the desaturase and elongase enzymes that participate in the PUFA biosynthesis pathway, as well as the peroxisomal beta-oxidation pathway increase with age suggesting the presence of a generalizable pattern. The reasons (dysfunctionality or adaptation?) for the increase in these enzymatic activities during aging remain unknown. In any case, this pattern favors a high age-associated membrane unsaturation that, in turn, is highly susceptible to lipid peroxidation (independently of the presence or absence of an increase in age-associated ROS production, or defects in molecular removal or repair) and to the induction of a high steady-state level of lipoxidation derived molecular damage. Therefore, the available data tend to favor the view that the increase in membrane unsaturation is a key factor responsible for age-related accrual of molecular lipoxidative damage.

\section{ARE INTERSPECIES VARIATIONS IN LONGEVITY RELATED TO CORRESPONDING DIFFERENCES IN MEMBRANE UNSATURATION AND LIPOXIDATION-DERIVED MOLECULAR DAMAGE?}

The first indication of a connection between membrane fatty acid composition and maximum longevity was the report by Pamplona et al. (1996) which demonstrated that the PI of liver mitochondria from rats, pigeons and humans was strongly correlated with their respective longevity. Later, it was shown that this was the case for a wide range of tissues and animal species including mammals, birds, insects and crustaceans. Unfortunately, no data are currenly available for reptiles, amphibians, fishes, and many invertebrates.

Thus, it has been found that long-lived animals (birds and mammals, including humans) have a lower degree of total tissue and mitochondrial fatty acid unsaturation and PI than shortlived ones (Table 2). In agreement with this, it was demonstrated that in long-lived animal species a low degree of total tissue and mitochondrial fatty acid unsaturation was accompanied by a low sensitivity to in vivo and in vitro lipid peroxidation and a low steady-state level of lipoxidation-derived adducts in both tissue and mitochondrial proteins from organs like skeletal muscle, heart, liver, and brain (Pamplona et al., 2002a,b,c; Pamplona, 2008; Pamplona and Barja, 2011). Reinforcing this idea of low lipoxidative damage in long-lived species, lipofuscin also showed an accumulation rate that inversely correlates with longevity (Terman and Brunk, 2004). These findings were consistent with the negative correlation previously observed between longevity 
Table 2 | Comparative studies between membrane unsaturation (peroxidizability index, PI) and longevity in animal species (by chronological order).

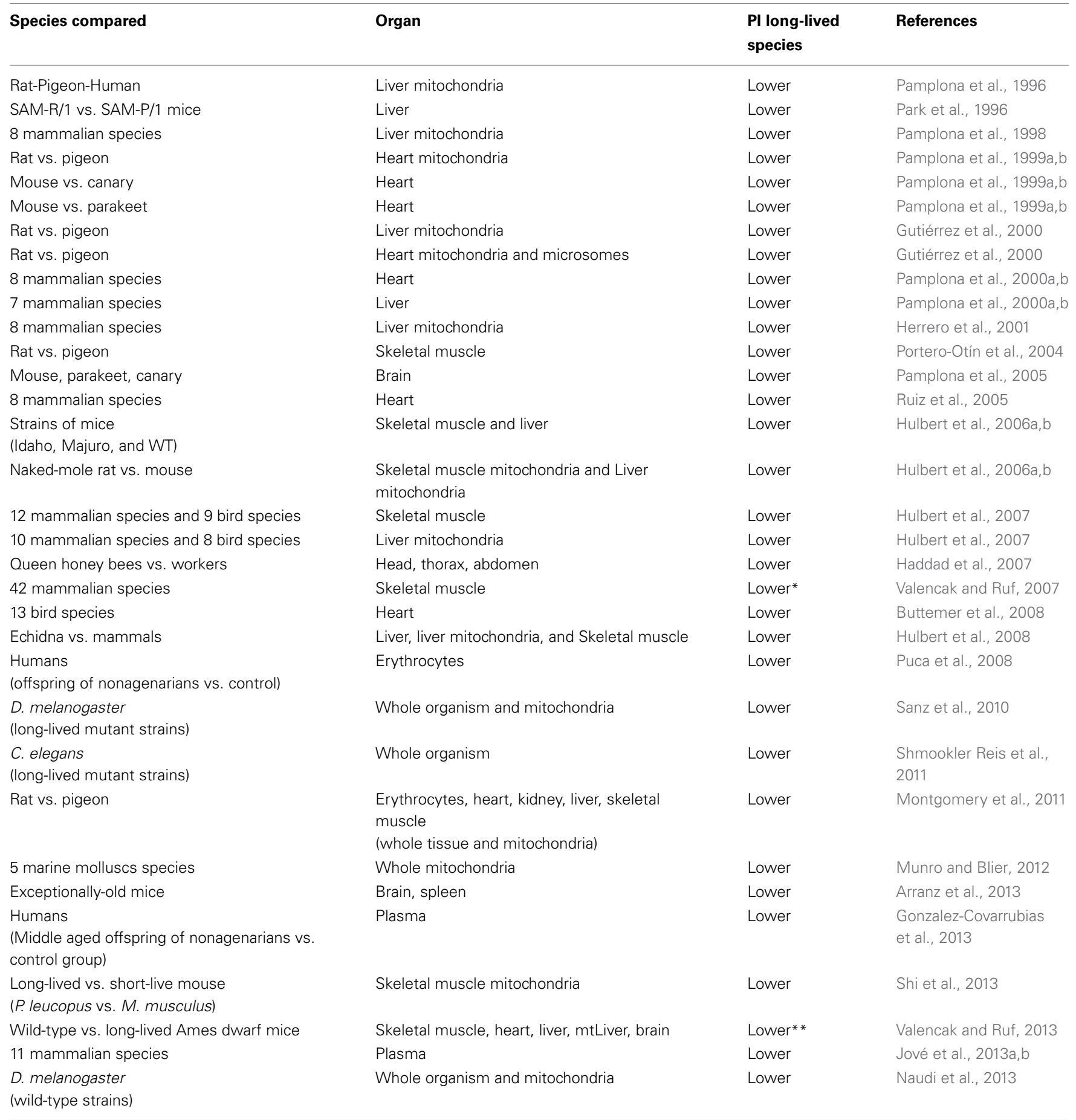

${ }^{*}$ Results obtained after correction for body weight and phylogeny showed that longevity decreases as the ratio of n-3 to n-6 PUFAs increases. No relation between longevity and PI was found; ${ }^{* *}$ No significant differences were observed for brain.

and the sensitivity to lipid autoxidation of mammalian kidney and brain homogenates (Cutler, 1985).

All these observations made at cell-tissue level can be interestingly extended to plasma lipids. Thus, in a recent study (Jové et al., 2013a,b) the plasma lipidomic profile by using high-throughput lipidome profiling technologies of 11 mammalian species ranging in maximum longevity from 3.5 to 120 years was determined. Using a non-targeted approach about 14,000 lipid species in plasma was detected, and the multivariate analyses separated perfectly 11 groups, indicating a specific signature for each animal 
species which accurately predicts animal longevity. Regression analysis between lipid species and longevity revealed that longchain free fatty acid concentrations, PI, and lipid peroxidationderived products correlated in a specific and significant way. Thus, the greater the longevity of a species, the lower is its plasma long-chain free fatty acid concentration, peroxidizability, and lipid peroxidation-derived products content, suggesting that the lipidomic signature is an optimized feature associated with animal longevity.

While longevity can differ dramatically between mammal and bird species, there can also be significant longevity differences within a species. Thus, populations of two wild-derived strains of mice display extended longevity (both mean and maximum longevity) compared to genetically heterogenous laboratory mice when kept under identical conditions (Miller et al., 2002). The PI of both skeletal muscle and liver phospholipids of the two wild-type mice strains with the extended longevity was significantly smaller than that of the laboratory mice (Hulbert et al., $2006 a, b)$. This is notable because, since the different mice strains were fed the identical diet, it shows that the differences in membrane fatty acid composition between species are not determined by dietary differences but is genetically regulated. In a similar way, in the senescence-accelerated mouse (SAM) strain, the SAM-prone mice had greater levels of the highly polyunsaturated peroxidation-prone fatty acids 22:6n-3 and 20:4n-6 and lower levels of the more peroxidation-resistant 18:2 n-6 PUFA in their membranes, and consequently had a greater PI than the SAM-resistant mice (Park et al., 1996). SAM-prone mice also showed greater degrees of lipid peroxides in their tissues than do SAM-resistant mice.

In this context, it is also of great interest to know and discern the degree of membrane unsaturation and the steady-state levels of lipoxidative damage in physiological systems from exceptionally long-lived specimens. Thus, in a recent work (Arranz et al., 2013), adult (28 weeks), old (76 weeks), and exceptionally old (128 weeks) BALB/c female mice were used. Brain and spleen were analyzed for membrane fatty acid composition and markers of lipoxidative molecular damage. The results showed significantly lower PI and lipoxidation-derived protein damage in brain and spleen from exceptionally old animals when compared to old specimens, and in a range analogous to adult animals. Therefore, low susceptibility to lipid peroxidation and maintenance of adult-like molecular lipoxidative damage could be key factors for longevity achievement.

Comparing biological processes in closely-related species with divergent longevity can also be a powerful approach to study mechanisms of longevity. Thus, the skeletal muscle mitochondria from long-lived white-footed mouse Peromyscus leucopus (MLSP $=8$ years) display lower levels of isoprostanes (lipid peroxidation-derived compounds) than the common laboratory mouse, Mus musculus (MLSP = 3.5 years) (Shi et al., 2013).

Two exceptionally long-living mammalian species (naked mole-rats and echidnas) also have membrane fatty acid profiles that are resistant to lipid peroxidation as one would predict from their longevities. Thus, when membrane fatty acid composition was measured in tissues from naked mole-rats, the longest-living rodents known with a recorded longevity exceeding 28 years
(Buffenstein, 2005), it was found that they have very low levels of 22:6n-3 in their tissue phospholipids compared to mice. Although both mice and naked mole-rats have similar levels of total UFAs in their tissue phospholipids, the low 22:6n-3 levels of the naked mole-rats result in lower PI and more peroxidationresistant membranes in skeletal muscle and liver mitochondria (Hulbert et al., 2006a,b; Mitchell et al., 2007). In a similar way, the echidna Tachyglossus aculeatus, a monotreme mammal from Australia that is exceptionally long-living with a documented longevity of 50 years, also had a membrane composition resistant to lipid peroxidation (Hulbert et al., 2008). Accordingly, membrane lipids of echidna tissues (skeletal muscle, liver, and liver mitochondria) were found to have a lower content of PUFAs and a higher content of MUFAs, resulting in a low PI and, consequently, indicating that the cellular membranes of echidnas is peroxidation-resistant (Hulbert et al., 2008).

Honeybees (Apis mellifera) and flyes (D. melanogaster) provide another example of variation in longevity within a species that extend previous findings in vertebrates to invertebrates. In the honey bee, depending on what they are fed, female eggs become either workers or queens (Winston, 1987). Hence, queens and workers share a common genome. However, the longevity of queens is an order-of-magnitude greater than that of workers. In order to test if differences in membrane composition could be involved the fatty acid composition of phospholipids of queen and worker honey bees were compared (Haddad et al., 2007). The cell membranes of both young and old honey bee queens were highly monounsaturated with very low content of PUFAs. Newly emerged workers show a similar membrane fatty acid composition to queens but within the first week of hive life, they increase the polyunsaturate and decrease the monounsaturate lipid content of their membranes, possibly due to the activation of a genetic program and metabolic reprogrammation resulting from pollen consumption. This means that their membranes likely become more susceptible to lipid peroxidation in this first week of hive life. So, the results again support the suggestion that membrane composition might be an important factor in the determination of longevity. In another approach, these predictions have also been tested in a comparison among three wild type strains of D. melanogaster differing in their longevities (a long-lived strain: Oregon R, and two short-lived strains: Canton $\mathrm{S}$ and Dahomey). The results also confirm the presence of an inverse correlation between membrane unsaturation and lipoxidation-derived molecular damage and longevity. So, the greater the longevity of the Drosophila strain, the lower is the membrane unsaturation (Naudi et al., 2013).

Recent studies show that bivalves are excellent models for longevity research (Abele et al., 2009; Philipp and Abele, 2010). This taxonomic group includes the longest-living non-colonial metazoan (the Iceland clam Arctica islandica, MLSP $=507$ years; Wanamaker et al., 2008), as well as surf clams (= Family Donacidae) with species of no more than 1 year longevity. Two traits make bivalves excellent models for longevity research: first, bivalves from temperate and cold-water environments can be accurately aged by counting their annual shell growth rings. This makes it possible to relate physiological state to chronological age in wild populations. Secondly, bivalve molluscs are genetically 
intermediate to classical invertebrate models of longevity (e.g., worms and flies) and mammals. This provides an opportunity to study the evolution of oxidative stress response pathways and animal longevity (Austad, 2009; Philipp and Abele, 2010). In this scenario, a recent study (Munro and Blier, 2012) analyzed the possible existence of a PI vs. longevity relationship by comparing the phospholipid fatty acid composition from mitochondrial membranes and other cell membranes of the longest-living metazoan species (Arctica islandica, 507 years) to four other sympatric bivalve molluscs also differing in their longevities $(28,37$, 92, and 106 years, respectively). The results certified that longlived marine bivalves possess peroxidation-resistant membranes. Indeed there is a significant inverse correlation between PI and longevity, analogously to the described findings from vertebrates (mammals and birds) (Hulbert et al., 2007).

A final specific comment concerning humans, as exceptionally long-lived species, is also pertinent. The findings from a recent work centered in offspring of long-lived individuals again seem to reinforce the association between membrane unsaturation and longevity. Thus, the fatty acid composition and PI of erythrocyte membranes from 41 nonagenarian offspring were compared with 30 matched controls (Puca et al., 2008). The results of this study demonstrated a lower PI in the lipid composition of erythrocyte membranes derived from nonagenarian offspring versus matched controls. This is indicative of reduced susceptibility to oxidative stress and increased membrane integrity at the cellular level for nonagenarian offspring compared with the general population under investigation. In this context, it should be plausible to infer that lipid composition of erythrocyte membranes could represent a useful biomarker of longevity. Finally, with the idea to investigate which specific lipids associate with familial longevity, another study (Gonzalez-Covarrubias et al., 2013) has explored the plasma lipidome in 1526 middle-aged offspring of nonagenarians (59 years) and 675 (59 years) controls from the Leiden Longevity Study. In men, no significant differences were observed between offspring and controls; whereas in women, 19 lipid species were related to familial longevity. More interestingly, the longevity-linked lipidomic profile showed by female offspring expressed a higher ratio of MUFA over PUFA lipid species revealing a plasma lipidome more resistant to oxidative stress.

Overall, all these comparisons (a) support an important role for membrane fatty acid composition in the determination of longevity, (b) reinforce the idea that the connection between membrane unsaturation and longevity is not restricted to vertebrates, and (c) suggest that membrane composition is regulated in a species-specific way.

\section{ARE EXPERIMENTAL EXTENSIONS IN LONGEVITY BY GENETIC MANIPULATIONS ACCOMPANIED BY ATTENUATIONS OF MEMBRANE UNSATURATION AND LIPOXIDATION-DERIVED MOLECULAR DAMAGE?}

The relevance of membrane unsaturation in determining longevity has also been recently reinforced by using Drosophila as an experimental model (Sanz et al., 2010). In this study, transgenic strains of Drosophila that express yeast NDI1ubiquitously were created (in yeast, the single-subunit NADH dehydrogenase Ndil serves as a non-proton-translocating alternative enzyme that replaces complex I, bringing about the reoxidation of intramitochondrial NADH). NDI1 expression bring about a decreased accumulation of lipoxidation-derived damage markers, accompanied by a reduced rate of ROS production and restored bioenergetic state, resulting in an increased longevity. This lower lipoxidation-derived damage in the long-lived strains is also linked to an adaptive response with a low degree in membrane unsaturation (Naudi et al., 2013).

In C. elegans as experimental model (Hulbert, 2011; Shmookler Reis et al., 2011), it was analyzed the fatty acid profile of lipids extracted from strains of $C$. elegans that vary in longevity by $\sim 10$-fold, and display several significant log-linear correlations between longevity and fatty acid composition. The results - strongly influenced by two mutant strains (daf- 2 and age-1, both long-lived mutant strains linked to a dysruption of the insulin like-signaling pathway) that showed the greatest longevities-demonstrated that comparing the shortest-living with longest-living strains total MUFAs increased from 34 to $48 \%$, total PUFAs decreased from 37 to $26 \%$, and PI decreased from 141 to 81 . All together, these findings suggest that mutations leading to higher longevities require of, at least, an adaptation of the degree of membrane unsaturation.

Functional assays, using RNAi to attenuate gene expression, might provide evidence that such genes (e.g., for desaturase or detoxifying enzymes) play causal roles in enhancing longevity. Longevity extensions permit stronger inferences than its decrease, due to the many ways longevity could be shortened upon disruption of any pathway that contributes to survival. In this context, two studies made on C. elegans related to the PUFA biosynthesis and detoxifiying enzymes for RCS deserve a special mention.

As mentioned above, RCS are compounds produced under oxidative stress conditions. These compounds are detoxified in multiple ways, including conjugation to glutathione, oxidation by aldehyde dehydrogenases, or reduction by aldoketoreductases (Pamplona, 2008). Reaction of RCS with gluthathione can proceed in one of two ways: by nonenzymatic conjugation or through glutathione transferase (GST)-mediated conjugation to form Michael adducts. GSTs belong to a supergene family of multifunctional enzymes, which are particularly involved in the detoxification of highly reactive aldehydes (Sheehan et al., 2001). Interestingly, protection against oxidative stress is the major driver of positive selection in mammalian GSTs, explaining the overall expansion pattern of this enzymes' family. The biological relevance of this protein-enzyme family is highlighted by studies in C. elegans demonstrating that interference with the expression of these enzymes significantly shortens the longevity of the organism and increases the formation of lipoxidation-derived protein adducts (Ayyadevara et al., 2007), whereas the overexpression of GSTs increases the longevity (Ayyadevara et al., 2005). Consequently, in this approach, the relationship between longevity and the expression of the detoxifiying enzymes indicates that the substrate of that enzyme, reactive carbonyl compounds, may be causally involved in limiting longevity. In the other approach, C. elegans benefits from RNAi suppression of genes encoding either of two elongases or a delta-5 desaturase, fat-4, whereas knochdowns of delta- 9 
desaturase genes can slightly reduce longevity (Shmookler Reis et al., 2011). Taken together, these functional data imply that the modulation of fatty acid composition to increase resistance to lipid peroxidation is one of the mechanisms for longevity extension.

\section{ARE EXPERIMENTAL EXTENSIONS IN LONGEVITY BY NUTRITIONAL INTERVENTIONS ACCOMPANIED BY ATTENUATIONS OF MEMBRANE UNSATURATION AND LIPOXIDATION-DERIVED MOLECULAR DAMAGE?}

This question is a key issue that goes beyond correlation to establish a causative role for membranes and lipoxidative stress in the determination of longevity. In order to clarify whether the low membrane unsaturation of long-lived animals protects their cellular components from lipid oxidation and lipoxidation-derived molecular damage, studies of experimental dietary modification of in vivo membrane fatty acid unsaturation have been performed (Herrero et al., 2001; Portero-Otin et al., 2003; Pamplona et al., 2004). These studies were specially designed to partially circumvent the homeostatic system of compensation of dietaryinduced changes in membrane unsaturation which operates at tissue level. The obtained findings demonstrate that lowering the membrane unsaturation of cellular membranes protects tissues against lipid peroxidation and lipoxidation-derived macromolecular damage.

Available evidences in favor for a relationship between membrane unsaturation and longevity proceed from nutritional interventions that extend longevity in experimental models. So, caloric (CR), as well as protein (PR) and methionine (MetR) restriction attenuates age-related changes in the degree of membrane unsaturation and the level of lipoxidation products in a variety of tissues and animal species (Yu, 2005; Pamplona and Barja, 2006, 2011; Jové et al., 2013a,b). Thus, a decrease in membrane unsaturation, lipid peroxidation and lipoxidation-derived damage has been reported in tissues like liver, heart, and brain from these dietary restrictions in rats and mice (Laganiere and Yu, 1987; Pamplona et al., 2002a,b,c; Lambert et al., 2004; Sanz et al., 2005, 2006; Ayala et al., 2007; Gómez et al., 2007; Naudí et al., 2007; Caro et al., 2008, 2009; Jové et al., 2013a,b). CR has also been shown to reduce levels of lipofuscin in tissues of rodents and C. elegans (Enesco and Kruk, 1981; De et al., 1983; Rao et al., 1990; Terman and Brunk, 2004; Gerstbrein et al., 2005).

From these studies it can be inferred that the magnitude of the change is modest for membrane unsaturation (between 2.5-10\%) compared to that for the lipoxidation-derived molecular damage (between 20-40\%) likely due to the added effect of the lower mitochondrial ROS generation also induced by these nutritional interventions. In addition to the moderate but significant effect on membrane unsaturation, these nutritional interventions show an effect directly related to the intensity of the dietary restriction applied, being both PR and MetR even more intense and effective that CR. It is suggested from available data that the effects of CR on membrane unsaturation could be divided in three stages depending of CR duration in rats. During short-term $\mathrm{CR}$ periods, decreases in the rate of mitochondrial ROS production and lipoxidation-derived protein damage are observed in some tissues together with minor changes in membrane fatty acid composition. If CR is applied for several weeks-months, changes in particular fatty acids with moderate or no changes in PI occur, although the magnitude of the changes depends on the organ and the intensity of the restriction. Finally, in long-term CR, the beneficial effects on ROS production, PI and lipoxidationderived damage are evident. In fact, CR diminishes the slope of the relationship between age and age-related lipid peroxidation. Thus, the CR manipulation seems to trigger an adaptive response protecting the most basic requirements of membrane integrity.

Very valuable information could be also obtained from studies designed to modify membrane fatty acid composition in order to increase membrane unsaturation and to evaluate its impact in animal longevity. Thus, in a recent study (Tsuduki et al., 2011) the influence of long-term ingestion of fish oil (a PUFAn-3 rich oil) on lipid oxidation and longevity was examined in senescenceaccelerated (SAMP8) mice. Male mice were fed a fish oil diet (5\% fish oil and 5\% safflower oil) or a safflower oil diet (10\% safflower oil) from 12 weeks of age. The SAMP8 mice fed fish oil showed a significantly reduced longevity, in association with a higher lipid peroxidation, when compared to mice fed safflower oil.

Reinforcing this outcome, there is also a reduction in $C$. elegans longevity with the addition of PUFAs to their diet (Shmookler Reis et al., 2011). Thus, adult worms were maintained on agar plates spotted with E. coli (strain OP50). Control plates were unsupplemented, while treatment plates contained either palmitic acid (16:0) or eicosapentaenoic acid (20:5n-3). The results showed that longevity in the presence of 20:5n-3 was reduced $20 \%$ relative to unaugmented controls, and by $16 \%$ relative to worms supplemented with 16:0. In an independent experiment, supplementation with 22:6n-3 produced similar reductions in survival, $24 \%$ relative to untreated controls and $15 \%$ relative to palmitic acid. In contrast to these results, in another study (Hillyard and German, 2009) it is described a beneficial effect of these molecules (20:5n-3 and 22:6n-3) when added to the shortlived mutant fat-3, which lacks a functional delta-6 desaturase, and thus PUFAs including 20:5n-3.

\section{MECHANISM RESPONSIBLE FOR THE LONGEVITY-RELATED DIFFERENCES IN MEMBRANE UNSATURATION}

The low PI observed in long-lived species are due to changes in the type of unsaturated fatty acid that participates in membrane composition (Pamplona et al., 2002a,b,c; Hulbert et al., 2007). Globally, there is a systematic redistribution between the types of PUFAs present from highly unsaturated fatty acids such as $22: 6 n-3,20: 5 n-3$, and 20:4n-6 in short-lived animals to the less unsaturated 18:3n-3, 18:2n-6, and 18:1 in the long-lived ones, at mitochondrial and tissue level. Furthermore, the PI of the respective diets did not correlate with longevity. This indicates again that the contribution of the variations in the degree of unsaturation of dietary fats to the inter-species differences is, if any, very modest.

The mechanisms responsible for the longevity-related differences in fatty acid profile can be related, in principle, to the PUFAs biosynthesis pathway (including desaturases, elongases, and peroxisomal beta-oxidation; see Figure 1), and the deacylationreacylation cycle. The available estimates of delta-5 and delta- 6 
Membrane unsaturation as a dynamic structural adaptive system

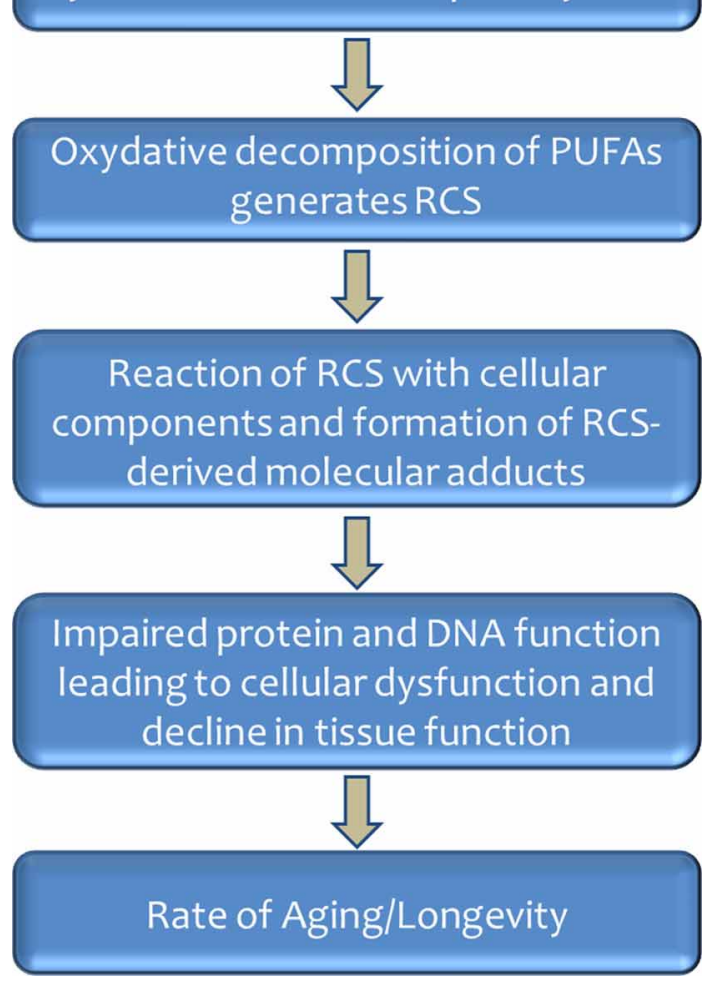

FIGURE 3 | Role of membrane unsaturation and lipoxidation-derived molecular damage in aging and longevity.

desaturase activities, as well as different elongase activities, indicate that they are several folds lower in long-lived species than in short-lived ones (Pamplona et al., 2002a,b,c; Pamplona and Barja, 2003; Hulbert et al., 2007; Shmookler Reis et al., 2011). This can explain why e.g., 22:6n-3 and 20:4n-6 decreases and 18:2n-6 and 18:3n-3 increases, from short-to long-lived animals, since elongases/desaturases are the rate-limiting enzymes of the $n-3$ and $n-6$ pathways synthesizing the highly unsaturated PUFAs 20:4n-6 and 22:6n-3 from their dietary precursors, 18:2n-6 and 18:3n-3, respectively. Thus, elongation-desaturation pathways would make available in situ the $n-6$ and $n-3$ fatty acids to phospholipid acyltransferases in order to remodel the phospholipid acyl groups. In addition, a relevant role for peroxisomal beta-oxidation, a metabolic pathway key for the obtention of 20:5n-6 and 22:6n-3 should be also considered to the light of recent results.

In accordance with this interpretation, a recent study (Jobson et al., 2010) with a phylogenomic approach to identify the genetic targets of natural selection for extended longevity in mammals has been published. The premise of this work is that genes preventing high rates of aging should be under stronger selective pressure in long-lived species, relative to short-lived ones. In other words, long-lived species should allow identifying a stronger level of amino acid conservation from specific genes than short-lived ones. The results obtained by comparing the nonsynonymous and synonymous evolution of 5.7 million codon sites across 25 species proved that genes involved in fatty acid biosynthesis (elongases, desaturases, and lipoxidation repair), as well as extracellular collagen composition, have collectively undergone increased selective pressure in long-lived species, whereas genes involved in DNA replication/repair or antioxidants, among others, have not.

More investigations are, however, needed to confirm the role of these metabolic pathways in aging and longevity, and to extend them to the potential role of regulatory and transcriptional factors involved in PUFA metabolism.

\section{THE BIOLOGICAL MEMBRANE AS DYNAMIC STRUCTURAL ADAPTIVE SYSTEM}

Animals with a high longevity have a low degree of membrane fatty acid unsaturation based on the redistribution between types of PUFAs. This may be viewed as an elegant evolutionary strategy, because it decreases the sensitivity to lipid peroxidation and lipoxidation-derived damage to cellular macromolecules without strongly altering fluidity/microviscosity, a fundamental property of cellular membranes for the proper function of e.g., receptors, ion pumps, and transport of metabolites. This would occur because membrane fluidity increases acutely with the introduction of the first and less with the second double bond (due to their introduction of "kinks" in the fatty acid molecule), whereas additional (the third and following) double bonds cause few further variations in fluidity (Brenner, 1984). This is so because the kink has a larger impact on fluidity when the double bond is situated near the center of the fatty acid chain (first double bond) than when it is situated progressively nearer to its extremes (next double bond additions). In the case of the sensitivity to lipid peroxidation, however, PI increase irrespective of the double bond location at the center or laterally on the fatty acids (Holman, 1954). Thus, by switching fatty acids with four or six double bonds by those having only one, two (or even three) double bonds, the sensitivity to lipid peroxidation is strongly decreased in long-lived animals, whereas the fluidity of the membrane would be essentially maintained. This hypothesis, reminiscent of membrane acclimation to different environments at PUFA level in poikilotherms and bacteria, has been termed homeoviscous longevity adaptation (Pamplona et al., 2002a,b,c), and displays the biological membranes as a dynamic structural adaptive system (see Figure 3).

\section{ACKNOWLEDGMENTS}

Investigations of the author of this review have been supported in part by $\mathrm{I}+\mathrm{D}$ grants from the Spanish Ministry of Science and Innovation (BFU2011-23888), and BSCH-UCM (2009-2010) to Gustavo Barja; and grants from the Spanish Ministry of Education and Science (BFU2009-11879/BFI), the Spanish Ministry of Economy and Competitiveness-Institute of Health Carlos III (PI13/00584) and the Generalitat of Catalunya (2009SGR735) to Reinald Pamplona. The authors are grateful to the anonymous reviewers for criticisms and suggestions, which improved the manuscript. 


\section{REFERENCES}

Abele, D., Brey, T., and Philipp, E. (2009). Bivalve models of aging and the determination of molluscan lifespans. Exp. Gerontol. 44, 307-315. doi: 10.1016/j.exger.2009.02.012

Arranz, L., Naudí, A., De la Fuente, M., and Pamplona, R. (2013). Exceptionally old mice are highly resistant to lipoxidation-derived molecular damage. Age (Dordr) 35, 621-635. doi: 10.1007/s11357-012-9391-0

Austad, S. N. (2009). Is there a role for new invertebrate models for aging research? J. Gerontol. A Biol. Sci. Med. Sci. 64, 192-194. doi: 10.1093/gerona/ gln059

Ayala, V., Ilieva, E. V., Fernandez, E., Modol, M. T., Bellmunt, M. J., Prat, J., et al. (2006). Lesión oxidativa de proteínas de hígado y corazón de rata durante el proceso de envejecimiento. Rev. Esp. Geriatr. Gerontol. 41, 43-49. doi: 10.1016/S0211-139X(06)72922-5

Ayala, V., Naudí, A., Sanz, A., Caro, P., Portero-Otin, M., Barja, G., et al. (2007). Dietary protein restriction decreases oxidative protein damage, peroxidizability index, and mitochondrial complex I content in rat liver. J. Gerontol. A Biol. Sci. Med. Sci. 62, 352-360. doi: 10.1093/gerona/62.4.352

Ayyadevara, S., Dandapat, A., Singh, S. P., Siegel, E. R., Shmookler Reis, R. J., Zimniak, L., et al. (2007). Life span and stress resistance of Caenorhabditis elegans are differentially affected by glutathione transferases metabolizing 4-hydroxynon-2-enal. Mech. Ageing Dev. 128, 196-205. doi: 10.1016/j.mad.2006.11.025

Ayyadevara, S., Engle, M. R., Singh, S. P., Dandapat, A., Lichti, C. F., Benes, H., et al. (2005). Lifespan and stress resistance of Caenorhabditis elegans are increased by expression of glutathione transferases capable of metabolizing the lipid peroxidation product 4-hydroxynonenal. Aging Cell 4, 257-271. doi: 10.1111/j.1474-9726.2005.00168.x

Bielski, B. H., Arudi, R. L., and Sutherland, M. W. (1983). A study of the reactivity of HO2/O2-with unsaturated fatty acids. J. Biol. Chem. 258, 4759-4761.

Brand, M. D., Affourtit, C., Esteves, T. C., Green, K., Lambert, A. J., Miwa, S., et al. (2004). Mitochondrial superoxide: production, biological effects, and activation of uncoupling proteins. Free Radic. Biol. Med. 37, 755-767. doi: 10.1016/j.freeradbiomed.2004.05.034

Brenner, R. R. (1984). Effect of unsaturated fatty acids on membrane structure and enzyme kinetics. Progr. Lipid Res. 23, 69-96. doi: 10.1016/0163-7827(84) 90008-0

Brigelius-Flohé, R. (2006). Glutathione peroxidases and redox-regulated transcription factors. Biol. Chem. 387, 1329-1335. doi: 10.1515/BC.2006.166

Buffenstein, R. (2005). The naked mole-rat: a new long-living model for human aging research. J. Gerontol. A Biol. Sci. Med. Sci. 60, 1369-1377. doi: 10.1093/gerona/60.11.1369

Buttemer, W. A., Battam, H., and Hulbert, A. J. (2008). Fowl play and the price of petrel: long-living Procellariiformes have peroxidation-resistant membrane composition compared with short-living Galliformes. Biol. Lett. 4, 351-354. doi: 10.1098/rsbl.2008.0145

Caro, P., Gómez, J., López-Torres, M., Sánchez, I., Naudí, A., Jove, M., et al. (2008). Forty percent and eighty percent methionine restriction decrease mitochondrial ROS generation and oxidative stress in rat liver. Biogerontology 9, 183-196. doi: 10.1007/s10522-008-9130-1

Caro, P., Gomez, J., Sanchez, I., Naudi, A., Ayala, V., López-Torres, M., et al. (2009). Forty percent methionine restriction decreases mitochondrial oxygen radical production and leak at complex I during forward electron flow and lowers oxidative damage to proteins and mitochondrial DNA in rat kidney and brain mitochondria. Rejuvenation Res. 12, 421-434. doi: 10.1089/rej. 2009.0902

Catalá, A. (2009). Lipid peroxidation of membrane phospholipids generates hydroxyl-alkenals and oxidized phospholipids active in physiological and/or pathological conditions. Chem. Phys. Lipids 157, 1-11. doi: 10.1016/j.chemphyslip.2008.09.004

Conrad, M., Schneider, M., Seiler, A., and Bornkamm, G. W. (2007). Physiological role of phospholipid hydroperoxide glutathione peroxidase in mammals. Biol. Chem. 388, 1019-1025. doi: 10.1515/BC.2007.130

Copple, I. M., Goldring, C. E., Kitteringham, N. R., and Park, B. K. (2008). The Nrf2-Keap1 defence pathway: role in protection against drug-induced toxicity. Toxicology 246, 24-33. doi: 10.1016/j.tox.2007.10.029

Cutler, R. G. (1985). Peroxide-producing potential of tissues: inverse correlation with longevity of mammalian species. Proc. Natl. Acad. Sci. U.S.A. 82, 4798-4802. doi: 10.1073/pnas.82.14.4798
De, A. K., Chipalkatti, S., and Aiyar, A. S. (1983). Some biochemical parameters of ageing in relation to dietary protein. Mech. Ageing Dev. 21, 37-48. doi: 10.1016/0047-6374(83)90014-3

Dobrosotskaya, I. Y., Seegmiller, A. C., Brown, M. S., Goldstein, J. L., and Rawson, R. B. (2002). Regulation of SREBP processing and membrane lipid production by phospholipids in Drosophila. Science 296, 879-883. doi: 10.1126/science. 1071124

Dowhan, W. (1997). Molecular basis for membrane phospholipid diversity: why are there so many lipids? Annu. Rev. Biochem. 66, 199-232. doi: 10.1146/annurev.biochem.66.1.199

Dowling, D. K., and Simmons, L. W. (2009). Reactive oxygen species as universal constraints in life-history evolution. Proc. Royal Soc. B Biol. Sci. 276, 1737-1745. doi: 10.1098/rspb.2008.1791

Echtay, K. S., Esteves, T. C., Pakay, J. L., Jekabsons, M. B., Lambert, A. J., Portero-Otín, M., et al. (2003). A signalling role for 4-hydroxy-2-nonenal in regulation of mitochondrial uncoupling. EMBO J. 22, 4103-4110. doi: 10.1093/emboj/cdg412

Embley, T. M., and Martin, W. (2006). Eukaryotic evolution, changes and challenges. Nature 440, 623-630. doi: 10.1038/nature04546

Enesco, H. E., and Kruk, P. (1981). Dietary restriction reduces fluorescent age pigment accumulation in mice. Exp. Gerontol. 16, 357-361. doi: 10.1016/05315565(81)90056-5

Esterbauer, H., Schaur, R. J., and Zollner, H. (1991). Chemistry and biochemistry of 4-hydroxynonenal, malonaldehyde and related aldehydes. Free Radic. Biol. Med. 11, 81-128. doi: 10.1016/0891-5849(91)90192-6

Fabelo, N., Martín, V., Marín, R., Santpere, G., Aso, E., Ferrer, I., et al. (2012). Evidence for premature lipid raft aging in APP/PS1 double-transgenic mice, a model of familial Alzheimer disease. J. Neuropathol. Exp. Neurol. 71, 868-881. doi: 10.1097/NEN.0b013e31826be03c

Fritz, K. S., and Petersen, D. R. (2013). An overview of the chemistry and biology of reactive aldehydes. Free Radic. Biol. Med. 59, 85-91. doi: 10.1016/j.freeradbiomed.2012.06.025

Gamliel, A., Afri, M., and Frimer, A. A. (2008). Determining radical penetration of lipid bilayers with new lipophilic spin traps. Free Radic. Biol. Med. 44, 1394-1405. doi: 10.1016/j.freeradbiomed.2007.12.028

Gerstbrein, B., Stamatas, G., Kollias, N., and Driscoll, M. (2005). In vivo spectrofluorimetry reveals endogenous biomarkers that report healthspan and dietary restriction in Caenorhabditis elegans. Aging Cell 4, 127-137. doi: 10.1111/j.1474-9726.2005.00153.x

Giles, G. I. (2009). "Redox-controlled transcription factors and gene expression," in Redox Signaling and Regulation in Biology and Medicine, eds C. Jacob, P. G. Winyard (Weinheim: Wiley-VCH Verlag GmbH\&Co. KGaA), 245-270.

Gómez, J., Caro, P., Naudí, A., Portero-Otin, M., Pamplona, R., and Barja, G. (2007). Effect of $8.5 \%$ and $25 \%$ caloric restriction on mitochondrial free radical production and oxidative stress in rat liver. Biogerontology 8, 555-566. doi: 10.1007/s10522-007-9099-1

Gonzalez-Covarrubias, V., Beekman, M., Uh, H. W., Dane, A., Troost, J., Paliukhovich, I., et al. (2013). Lipidomics of familial longevity. Aging Cell 12, 426-434. doi: 10.1111/acel.12064

Guillou, H., Zadravec, D., Martin, P. G., and Jacobsson, A. (2010). The key roles of elongases and desaturases in mammalian fatty acid metabolism: insights from transgenic mice. Prog. Lipid Res. 49, 186-199. doi: 10.1016/j.plipres.2009. 12.002

Gutiérrez, A. M., Reboredo, G. R., Arcemis, C. J., and Catalá, A. (2000). Nonenzymatic lipid peroxidation of microsomes and mitochondria isolated from liver and heart of pigeon and rat. Int. J. Biochem. Cell Biol. 32, 73-79. doi: 10.1016/S1357-2725(99)00105-3

Haddad, L. S., Kelbert, L., and Hulbert, A. J. (2007). Extended longevity of queen honey bees compared to workers is associated with peroxidation-resistant membranes. Exp. Gerontol. 42, 601-609. doi: 10.1016/j.exger.2007.02.008

Halliwell, B. (1999). Antioxidant defence mechanisms: from the beginning to the end (of the beginning). Free Radic. Res. 31, 261-272. doi: 10.1080/10715769900300841

Halliwell, B., and Gutteridge, J. M. C. (2007). Free Radicals in Biology and Medicine. New York, NY: Oxford University Press.

Herrero, A., Portero-Otín, M., Bellmunt, M. J., Pamplona, R., and Barja, G. (2001). Effect of the degree of fatty acid unsaturation of rat heart mitochondria on their rates of $\mathrm{H} 2 \mathrm{O} 2$ production and lipid and protein oxidative damage. Mech. Ageing Dev. 122, 427-443. doi: 10.1016/S0047-6374(01)00214-7 
Higdon, A., Diers, A. R., Oh, J. Y., Landar, A., and Darley-Usmar, V. M. (2012). Cell signaling by reactive lipid species: new concepts and molecular mechanisms. Biochem. J. 442, 453-464. doi: 10.1042/BJ20111752

Hillyard, S. L., and German, J. B. (2009). Quantitative lipid analysis and life span of the fat-3 mutent of Caenorhabditis elegans. J. Agric. Food Chem. 57, 3389-3396. doi: $10.1021 /$ jf8031414

Holman, R. T. (1954). "Autoxidation of fats and related substances," in Progress in Chemistry of Fats and Other Lipids, eds R. T. Holman, W. O. Lundberg, and T. Malkin (London: Pergamon Press), 51-98.

Hulbert, A. J. (2011). Longevity, lipids and C. Elegans. Aging 3, 81-82.

Hulbert, A. J., Beard, L. A., and Grigg, G. C. (2008). The exceptional longevity of an egg-laying mammal, the short-beaked echidna (Tachyglossus aculeatus) is associated with peroxidation-resistant membrane composition. Exp. Gerontol. 43, 729-733. doi: 10.1016/j.exger.2008.05.015

Hulbert, A. J., Faulks, S. C., and Buffenstein, R. (2006a). Oxidation-resistant membrane phospholipids can explain longevity differences among the longestliving rodents and similarly-sized mice. J. Gerontol. A Biol. Sci. Med. Sci. 61, 1009-1018. doi: 10.1093/gerona/61.10.1009

Hulbert, A. J., Faulks, S. C., Harper, J. M., Miller, R. A., and Buffenstein, R. (2006b). Extended longevity of wild-derived mice is associated with peroxidation-resistant membranes. Mech. Ageing Dev. 127, 653-657. doi: 10.1016/j.mad.2006.03.002

Hulbert, A. J., Pamplona, R., Buffenstein, R., and Buttemer, W. A. (2007). Life and death: metabolic rate, membrane composition, and life span of animals. Physiol. Rev. 87, 1175-1213. doi: 10.1152/physrev.00047.2006

Imai, H., and Nakagawa, Y. (2003). Biological significance of phospholipid hydroperoxide glutathione peroxidase (PHGPx, GPx4) in mammalian cells. Free Radic. Biol. Med. 34, 145-169. doi: 10.1016/S0891-5849(02) 01197-8

Itoh, Y. H., Sugai, A., Uda, I., and Itoh, T. (2001). The evolution of lipids. Adv. Space Res. 28, 719-724. doi: 10.1016/S0273-1177(01)00321-0

Jacobson, J., Lambert, A. J., Portero-Otín, M., Pamplona, R., Magwere, T., Miwa, S., et al. (2010). Biomarkers of aging in Drosophila. Aging Cell 9, 466-477. doi: 10.1111/j.1474-9726.2010.00573.x

Jobson, R. W., Nabholz, B., and Galtier, N. (2010). An evolutionary genome scan for longevity-related natural selection in mammals. Mol. Biol. Evol. 27, 840-847. doi: 10.1093/molbev/msp293

Jové, M., Ayala, V., Ramírez-Núñez, O., Naudí, A., Cabré, R., Spickett, C. M., et al. (2013a). Specific lipidome signatures in central nervous system from methionine-restricted mice. J. Proteome Res. 12, 2679-2689. doi: $10.1021 / \mathrm{pr} 400064 \mathrm{a}$

Jové, M., Naudi, A., Aledo, J. C., Cabre, R., Ayala, V., Portero-Otin, M., et al. (2013b). Plasma long-chain free fatty acids predict mammalian longevity. Sci. Rep. 3, 3346. doi: 10.1038/srep03346

Laganiere, S., and Yu, B. P. (1987). Anti-lipoperoxidation action of food restriction. Biochem. Biophys. Res. Commun. 145, 1185-1191. doi: 10.1016/0006291X(87)91562-2

Laganiere, S., and Yu, B. P. (1993). Modulation of membrane phospholipid fatty acid composition by age and food restriction. Gerontology 39, 7-18. doi: 10.1159/000213509

Lambert, A. J., Portero-Otin, M., Pamplona, R., and Merry, B. J. (2004). Effect of aging and caloric restriction on specific markers of protein oxidative damage and membrane peroxidizability in rat liver mitochondria. Mech. Ageing Dev. 125, 529-538. doi: 10.1016/j.mad.2004.06.002

Lane, N. (2002). Oxygen. The Molecule That Made the World. New York, NY: Oxford University Press.

Lombard, J., López-García, P., and Moreira, D. (2012). The early evolution of lipid membranes and the three domains of life. Nat. Rev. Microbiol. 10, 507-515. doi: 10.1038/nrmicro2815

Magwere, T., Pamplona, R., Miwa, S., Martinez-Diaz, P., Portero-Otin, M., Brand, M. D., et al. (2006). Flight activity, mortality rates, and lipoxidative damage in Drosophila. J. Gerontol. A Biol. Sci. Med. Sci. 61, 136-145. doi: 10.1093/gerona/61.2.136

Maher, J., and Yamamoto, M. (2010). The rise of antioxidant signaling-The evolution and hermetic actions of Nrf2. Toxicol Appl. Pharmacol. 244, 4-15. doi: 10.1016/j.taap.2010.01.011

McCord, J. M. (2000). The evolution of free radicals and oxidative stress. Am. J. Med. 108, 652-659. doi: 10.1016/S0002-9343(00)00412-5
Miller, R. A., Harper, J. M., Dysko, R. C., Durkee, S. J., and Austad, S. N. (2002). Longer life spans and delayed maturation in wild-derived mice. Exp. Biol. Med. 227, 500-508.

Mitchell, T. W., Buffenstein, R., and Hulbert, A. J. (2007). Membrane phospholipid composition may contribute to exceptional longevity of the naked mole-rat (Heterocephalus glaber): a comparative study using shotgun lipidomics. Exp. Gerontol. 42, 1053-1062. doi: 10.1016/j.exger.2007.09.004

Moller, M., Botti, H., Batthyany, C., Rubbo, H., Radi, R., and Denicola, A. (2005). Direct measurement of nitric oxide and oxygen partitioning into liposomes and low density lipoprotein. J. Biol. Chem. 280, 8850-8854. doi: 10.1074/jbc.M413699200

Montgomery, M. K., Hulbert, A. J., and Buttemer, W. A. (2011). The long life of birds: the rat-pigeon comparison revisited. PLOS ONE 6:e24138. doi: 10.1371/journal.pone.0024138

Munro, D., and Blier, P. U. (2012). The extreme longevity of Arctica islandica is associated with increased peroxidation resistance in mitochondrial membranes. Aging Cell 11, 845-855. doi: 10.1111/j.1474-9726.2012.00847.x

Nakamura, M. T., and Nara, T. Y. (2004). Structure, function, and dietary regulation of delta6, delta5, and delta9 desaturases. Annu. Rev. Nutr. 24, 345-376. doi: 10.1146/annurev.nutr.24.121803.063211

Naudi, A., Ayala, V., Jove, M., Portero-Otin, M., Sriram, A., Sanz, A., et al. (2013). Membrane unsaturation contributes to stress resistance and longevity of wildtype and long-lived mutant strains of Drosophila melanogaster. FEBS. J. 280, 588-589.

Naudí, A., Caro, P., Jové, M., Gómez, J., Boada, J., Ayala, V., et al. (2007). Methionine restriction decreases endogenous oxidative molecular damage and increases mitochondrial biogenesis and uncoupling protein 4 in rat brain. Rejuvenation Res. 10, 473-484. doi: 10.1089/rej.2007.0538

Naudí, A., Jové, M., Ayala, V., Cabré, R., Portero-Otín, M., and Pamplona, R. (2013). Non-enzymatic modification of aminophospholipids by carbonylamine reactions. Int. J. Mol. Sci. 14, 3285-3313. doi: 10.3390/ijms14023285

Ohno-Iwashita, Y., Shimada, Y., Hayashi, M., and Inomata, M. (2010). Plasma membrane microdomains in aging and disease. Geriatr. Gerontol. Int. 10, S41-S52. doi: 10.1111/j.1447-0594.2010.00600.x

Pamplona, R. (2008). Membrane phospholipids, lipoxidative damage and molecular integrity: a causal role in aging and longevity. Biochim. Biophys. Acta 1777, 1249-1262. doi: 10.1016/j.bbabio.2008.07.003

Pamplona, R. (2011). Advanced lipoxidation end-products. Chem. Biol. Interact. 192, 14-20. doi: 10.1016/j.cbi.2011.01.007

Pamplona, R., and Barja, G. (2003). "Aging rate, free radical production, ans constitutive sensitivity to lipid peroxidation: insights from comparative studies," in Biology of Aging and its Modulation Series, Vol. 1. Aging at the Molecular Level, ed T. Van Zglinicki (New York: Kluwer Academic Publisher), 47-64.

Pamplona, R., and Barja, G. (2006). Mitochondrial oxidative stress, aging and caloric restriction: the protein and methionine connection. Biochim. Biophys. Acta 1757, 496-508. doi: 10.1016/j.bbabio.2006.01.009

Pamplona, R., and Barja, G. (2011). An evolutionary comparative scan for longevity-related oxidative stress resistance mechanisms in homeotherms. Biogerontology 12, 409-435. doi: 10.1007/s10522-011-9348-1

Pamplona, R., Barja, G., and Portero-Otín, M. (2002a). Membrane fatty acid unsaturation, protection against oxidative stress, and maximum life span: a homeoviscous-longevity adaptation?. Ann. N.Y. Acad. Sci. 959, 475-490. doi: 10.1111/j.1749-6632.2002.tb02118.x

Pamplona, R., Portero-Otin, M., Bellmunt, M. J., Gredilla, R., and Barja, G. (2002b). Aging increases Nepsilon-(carboxymethyl)lysine and caloric restriction decreases Nepsilon-(carboxyethyl)lysine and Nepsilon(malondialdehyde)lysine in rat heart mitochondrial proteins. Free Radic. Res. 36, 47-54. doi: 10.1080/10715760210165

Pamplona, R., Portero-Otín, M., Requena, J. R., Gredilla, R., and Barja, G. (2002c). Oxidative, glycoxidative and lipoxidative damage to rat heart mitochondrial proteins is lower after 4 months of caloric restriction than in age-matched controls. Mech. Ageing Dev. 123, 1437-1446. doi: 10.1016/S0047-6374(02) 00076-3

Pamplona, R., and Costantini, D. (2011). Molecular and structural antioxidant defences against oxidative stress in animals. Am. J. Physiol. Regul. Integr. Comp. Physiol. 301, R843-R863. doi: 10.1152/ajpregu.00034.2011

Pamplona, R., Portero-Otín, M., Requena, J. R., Thorpe, S. R., Herrero, A., and Barja, G. (1999a). A low degree of fatty acid unsaturation leads to lower lipid 
peroxidation and lipoxidation-derived protein modification in heart mitochondria of the longevous pigeon than in the short-lived rat. Mech. Ageing Dev. 106, 283-296. doi: 10.1016/S0047-6374(98)00121-3

Pamplona, R., Portero-Otín, M., Riba, D., Ledo, F., Gredilla, R., Herrero, A., et al. (1999b). Heart fatty acid unsaturation and lipid peroxidation, and aging rate, are lower in the canary and the parakeet than in the mouse. Aging (Milano) 11, 44-49. doi: 10.1016/j.cbi.2011.01.007

Pamplona, R., Portero-Otín, M., Riba, D., Requena, J. R., Thorpe, S. R., LópezTorres, M., et al. (2000a). Low fatty acid unsaturation: a mechanism for lowered lipoperoxidative modification of tissue proteins in mammalian species with long life spans. J. Gerontol. A Biol. Sci. Med. Sci. 55, B286-B291. doi: 10.1093/gerona/55.6.B286

Pamplona, R., Portero-Otín, M., Ruiz, C., Gredilla, R., Herrero, A., and Barja, G. (2000b). Double bond content of phospholipids and lipid peroxidation negatively correlate with maximum longevity in the heart of mammals. Mech. Ageing Dev. 112, 169-183. doi: 10.1016/S0047-6374(99)00045-7

Pamplona, R., Portero-Otín, M., Riba, D., Ruiz, C., Prat, J., Bellmunt, M. J., et al. (1998). Mitochondrial membrane peroxidizability index is inversely related to maximum life span in mammals. J. Lipid Res. 39, 1989-1994.

Pamplona, R., Portero-Otín, M., Sanz, A., Ayala, V., Vasileva, E., and Barja, G. (2005). Protein and lipid oxidative damage and complex I content are lower in the brain of budgerigards and canaries than in mice. Relation to aging rate. Age 27, 267-280. doi: 10.1007/s11357-005-4562-x

Pamplona, R., Portero-Otin, M., Sanz, A., Requena, J., and Barja, G. (2004). Modification of the longevity-related degree of fatty acid unsaturation modulates oxidative damage to proteins and mitochondrial DNA in liver and brain. Exp. Gerontol. 39, 725-733. doi: 10.1016/j.exger.2004.01.006

Pamplona, R., Prat, J., Cadenas, S., Rojas, C., Pérez-Campo, R., López-Torres, M., et al. (1996). Low fatty acid unsaturation protects against lipid peroxidation in liver mitochondria from long-lived species: the pigeon and human case. Mech. Ageing Dev. 86, 53-66. doi: 10.1016/0047-6374(95)01673-2

Park, J. W., Choi, C. H., Kim, M. S., and Chung, M. H. (1996). Oxidative status in senescence accelerated mice. J. Gerontol. A Biol. Sci. Med. Sci. 51, B337-B345. doi: 10.1093/gerona/51A.5.B337

Philipp, E. E., and Abele, D. (2010). Masters of longevity: lessons from long-lived bivalves-a mini-review. Gerontology 56, 55-65. doi: 10.1159/000221004

Portero-Otin, M., Bellmunt, M. J., Requena, J. R., and Pamplona, R. (2003). Protein modification by advanced Maillard adducts can be modulated by dietary polyunsaturated fatty acids. Biochem. Soc. Trans. 31, 1403-1405. doi: 10.1042/BST0311403

Portero-Otín, M., Bellmunt, M. J., Ruiz, M. C., Barja, G., and Pamplona, R. (2001). Correlation of fatty acid unsaturation of the major liver mitochondrial phospholipid classes in mammals to their maximum life span potential. Lipids 36, 491-498. doi: 10.1007/s11745-001-0748-y

Portero-Otín, M., Requena, J. R., Bellmunt, M. J., Ayala, V., and Pamplona, R. (2004). Protein nonenzymatic modifications and proteasome activity in skeletal muscle from the short-lived rat and long-lived pigeon. Exp. Gerontol. 39, 1527-1535. doi: 10.1016/j.exger.2004.08.001

Puca, A. A., Andrew, P., Novelli, V., Anselmi, C. V., Somalvico, F., Cirillo, N. A., et al. (2008). Fatty acid profile of erythrocyte membranes as possible biomarker of longevity. Rejuvenation Res. 11, 63-72. doi: 10.1089/rej.2007.0566

Rabini, R. A., Moretti, N., Staffolani, R., Salvolini, E., Nanetti, L., Franceschi, C., et al. (2002). Reduced susceptibility to peroxidation of erythrocyte plasma membranes from centenarians. Exp. Gerontol. 37, 657-663. doi: 10.1016/S05315565(02)00006-2

Rao, G., Xia, E., Nadakavukaren, M. J., and Richardson, A. (1990). Effect of dietary restriction on the age-dependent changes in the expression of antioxidant enzymes in rat liver. J. Nutr. 120, 602-609.

Ruiz, M. C., Ayala, V., Portero-Otín, M., Requena, J. R., Barja, G., and Pamplona, R. (2005). Protein methionine content and MDA-lysine protein adducts are inversely related to maximum life span in the heart of mammals. Mech. Ageing Dev. 126, 1106-1114. doi: 10.1016/j.mad.2005.04.005

Sanz, A., Caro, P., Ayala, V., Portero-Otin, M., Pamplona, R., and Barja, G. (2006). Methionine restriction decreases mitochondrial oxygen radical generation and leak as well as oxidative damage to mitochondrial DNA and proteins. FASEB J. 20, 1064-1073. doi: 10.1096/fj.05-5568com

Sanz, A., Gredilla, R., Pamplona, R., Portero-Otín, M., Vara, E., Tresguerres, J. A., et al. (2005). Effect of insulin and growth hormone on rat heart and liver oxidative stress in control and caloric restricted animals. Biogerontology 6, 15-26. doi: 10.1007/s10522-004-7380-0

Sanz, A., Soikkeli, M., Portero-Otín, M., Wilson, A., Kemppainen, E., McIlroy, G., et al. (2010). Expression of the yeast NADH dehydrogenase Ndil in Drosophila confers increased lifespan independently of dietary restriction. Proc. Natl. Acad. Sci. U.S.A. 107, 9105-9110. doi: 10.1073/pnas.0911539107

Schirrmeister, B. E., de Vos, J. M., Antonelli, A., and Bagheri, H. C. (2013). Evolution of multicellularity coincided with increased diversification of cyanobacteria and the Great Oxidation Event. Proc. Natl. Acad. Sci. U.S.A. 110, 1791-1796. doi: 10.1073/pnas.1209927110

Sheehan, D., Meade, G., Foley, V. M., and Dowd, C. A. (2001). Structure, function and evolution of glutathione transferases: implications for classification of nonmammalian members of an ancient enzyme superfamily. Biochem. J. 360, 1-16. doi: 10.1042/0264-6021:3600001

Shi, Y., Pulliam, D. A., Liu, Y., Hamilton, R. T., Jernigan, A. L., Bhattacharya, A., et al. (2013). Reduced mitochondrial ROS, enhanced antioxidant defense, and distinct age-related changes in oxidative damage in muscles of longlived Peromyscus leucopus. Am. J. Physiol. Regul. Integr. Comp. Physiol. 304, R343-R355. doi: 10.1152/ajpregu.00139.2012

Shmookler Reis, R. J., Xu, L., Lee, H., Chae, M., Thaden, J. J., Bharill, P., et al. (2011). Modulation of lipid biosynthesis contributes to stress resistance and longevity of C. elegans mutants. Aging 3, 125-147. doi: 10.1007/s00360-013-0786-8

Terman, A., and Brunk, U. T. (2004). Lipofuscin. Int. J. Biochem. Cell Biol. 36, 1400-1404. doi: 10.1016/j.biocel.2003.08.009

Thorpe, S. R., and Baynes, J. W. (2003). Maillard reaction products in tissue proteins: new products and new perspectives. Amino Acids 25, 275-281. doi: 10.1007/s00726-003-0017-9

Tomoiu, A., Larbi, A., Fortin, C., Dupuis, G., and Fulop, T. Jr. (2007). Do membrane rafts contribute to human immunosenescence? Ann. N.Y. Acad. Sci. 1100, 98-110. doi: 10.1196/annals.1395.008

Tsuchida, M., Miura, T., and Aibara, K. (1987). Lipofuscin and lipofuscin-like substances. Chem. Phys. Lipids 44, 297-325. doi: 10.1016/0009-3084(87)90055-7

Tsuduki, T., Honma, T., Nakagawa, K., Ikeda, I., and Miyazawa, T. (2011). Long-term intake of fish oil increases oxidative stress and decreases lifespan in senescence-accelerated mice. Nutrition 27, 334-337. doi: 10.1016/j.nut.2010.05.017

Valencak, T. G., and Ruf, T. (2007). N-3 polyunsaturated fatty acids impair lifespan but have no role for metabolism. Aging Cell 6, 15-25. doi: 10.1111/j.14749726.2006.00257.x

Valencak, T. G., and Ruf, T. (2013). Phospholipid composition and longevity: lessons from Ames dwarf mice. Age 35, 2303-2313. doi: 10.1007/s11357-0139533-z

Vance, D. E., and Vance, J. E. (1996). Biochemistry of Lipids, Lipoproteins and Membranes. Amsterdam: Elsevier Science BV.

Van Meer, G., Voelker, D. R., and Feigenson, G. W. (2008). Membrane lipids: where they are and how they behave. Nat. Rev. Mol. Cell Biol. 9, 112-124. doi: $10.1038 / \mathrm{nrm} 2330$

Wakabayashi, N., Dinkova-Kostova, A. T., Holtzclaw, W. D., Kang, M. I., Kobayashi, A., Yamamoto, M., et al. (2004). Protection against electrophile and oxidant stress by induction of the phase 2 response: fate of cysteines of the Keap 1 sensor modified by inducers. Proc. Natl. Acad. Sci. U.S.A. 101, 2040-2045. doi: 10.1073/pnas.0307301101

Wallis, J. G., Watts, J. L., and Browse, J. (2002). Polyunsaturated fatty acid synthesis: what will they think of next?. Trends Biochem. Sci. 27, 467-473. doi: 10.1016/S0968-0004(02)02168-0

Wanamaker, A. D. Jr., Heinemeier, J., Scourse, J. D., Richardson, C. A., Butler, P. G., Eiriksson, J., et al. (2008). Very long-lived mollusks confirm 17th century $\mathrm{AD}$ tephra-based radiocarbon reservoir ages for North Icelandic shelf waters. Radiocarbon 50, 399-412.

West, J. D., and Marnett, L. J. (2006). Endogenous reactive intermediates as modulators of cell signaling and cell death. Chem. Res. Toxicol. 19, 173-194. doi: 10.1021/tx050321u

Winston, M. L. (1987). The Biology of the Honey Bee. Cambridge MA: Harvard University Press.

Yeagle, P. (1993). The Membranes of Cells. San Diego, CA: Academic Press.

Yu, B. P. (2005). Membrane alteration as a basis of aging and the protective effects of calorie restriction. Mech. Ageing Dev. 126, 1003-1010. doi: 10.1016/j.mad.2005.03.020 
Yu, B. P., Suescun, E. A., and Yang, S. Y. (1992). Effect of age-related lipid peroxidation on membrane fluidity and phospholipase A2: modulation by dietary restriction. Mech. Ageing Dev. 65, 17-33. doi: 10.1016/0047-6374(92)90123-U

Zimniak, P. (2011). Relationship of electrophilic stress to aging. Free Radic. Biol. Med. 51, 1087-1105. doi: 10.1016/j.freeradbiomed.2011.05.039

Conflict of Interest Statement: The authors declare that the research was conducted in the absence of any commercial or financial relationships that could be construed as a potential conflict of interest.

Received: 03 May 2013; paper pending published: 03 June 2013; accepted: 29 November 2013; published online: 17 December 2013.
Citation: Naudí A, Jové M, Ayala V, Portero-Otín M, Barja G and Pamplona R (2013) Membrane lipid unsaturation as physiological adaptation to animal longevity. Front. Physiol. 4:372. doi: 10.3389/fphys.2013.00372

This article was submitted to Membrane Physiology and Membrane Biophysics, a section of the journal Frontiers in Physiology.

Copyright (c) 2013 Naudí, Jové, Ayala, Portero-Otín, Barja and Pamplona. This is an open-access article distributed under the terms of the Creative Commons Attribution License (CC BY). The use, distribution or reproduction in other forums is permitted, provided the original author(s) or licensor are credited and that the original publication in this journal is cited, in accordance with accepted academic practice. No use, distribution or reproduction is permitted which does not comply with these terms. 